\title{
Anemia Management in the China Dialysis Outcomes and Practice Patterns Study
}

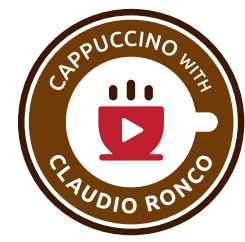

\author{
Li Zuo a,b Mia Wang ${ }^{g}$ Fanfan Hou ${ }^{c}$ Yucheng Yan ${ }^{d}$ Nan Chen ${ }^{\mathrm{e}}$ Jiaqi Qian ${ }^{\mathrm{d}}$ \\ Mei Wang ${ }^{b}$ Brian Bieberg Ronald L. Pisoni ${ }^{g}$ Bruce M. Robinsong ${ }^{g}$ Shuchi Anand ${ }^{f}$ \\ a Peking University Institute of Nephrology, Key Laboratory of Renal Disease, Ministry of Health of China, and \\ ${ }^{b}$ Department of Nephrology, Peking University People's Hospital, Beijing, 'Division of Nephrology, Nanfang Hospital, \\ Southern Medical University, Guangzhou, dRenal Division, Renji Hospital, Shanghai Jiaotong University School of \\ Medicine, and 'Division of Nephrology, Ruijin Hospital, Shanghai Jiaotong University School of Medicine, Shanghai, \\ China; ${ }^{f}$ Division of Nephrology, Stanford University, Palo Alto, Calif., and ${ }^{g}$ Arbor Research Collaborative for Health, \\ Ann Arbor, Mich., USA
}

\section{Key Words}

China - Domestic erythropoietin stimulating agents .

End-stage renal disease-related anemia $\cdot$ Intravenous iron

\begin{abstract}
Background: As the utilization of hemodialysis increases in China, it is critical to examine anemia management. Methods: Using data from the China Dialysis Outcomes and Practice Patterns Study (DOPPS), we describe hemoglobin ( $\mathrm{Hgb})$ distribution and anemia-related therapies. Results: Twenty one percent of China's DOPPS patients had $\mathrm{Hgb}<9 \mathrm{~g} / \mathrm{dl}$, compared with $\leq 10 \%$ in Japan and North America. A majority of medical directors targeted $\mathrm{Hgb} \geq 11$. Patients who were female, younger, or recently hospitalized had higher odds of $\mathrm{Hgb}<9$; those with insurance coverage or on twice weekly dialysis had lower odds of $\mathrm{Hgb}<9$. Iron use and erythropoietin-stimulating agents (ESAs) dose were modestly higher for patients with $\mathrm{Hgb}<9$ compared with $\mathrm{Hgb}$ in the range 10-12. Conclusion: A large proportion of hemodialysis patients in China's DOPPS do not meet the expressed Hgb targets. Less frequent hemodialysis, patient financial contribution, and lack of a substantial increase in ESA dose at lower $\mathrm{Hgb}$ concentrations may partially explain this gap.

Video Journal Club 'Cappuccino with Claudio Ronco' at http://www.karger.com/?doi=442741. @ $2016 \mathrm{~S}$. Karger AG, Basel
\end{abstract}

\section{Introduction}

As a growing number of patients with end-stage renal disease (ESRD) are able to access hemodialysis in China, the management of accompanying anemia requires a systematic study. Substantial resources and regulation are devoted to anemia management in countries with wellestablished dialysis practices. The use of erythropoietin stimulating agents (ESAs) is associated with improved functional status, quality of life, and lower requirements for blood transfusion compared to non-treatment [1-3]. At the same time, ESAs constitute the largest share of the costs of injectable drugs used in patients on dialysis in many countries $[4,5]$.

Only sparse data are available on the prevalence of anemia, anemia monitoring, and medication use for more than 100,000 patients undergoing hemodialysis in China [6]. We can expect significant heterogeneity in this nascent and rapidly expanding setting, where several unique factors come into play [7]. For example, the costs of monitoring and therapy are important considerations, since a majority of patients do not have full insurance coverage $[8,9]$. Even among patients who do have insurance coverage, ESA use may be limited if the patients' overall health care costs exceed a stipulated reimbursement cap. Two-times weekly hemodialysis is more com-

\section{KARGER}

E-Mail karger@karger.com

www.karger.com/bpu
(C) 2016 S. Karger AG, Base

0253-5068/16/0421-0033\$39.50/0
Li Zuo, MD, $\mathrm{PhD}$

Unit 10C in Ward Building

11 Xizhimennan Street, Xicheng District

Beijing 100044 (China)

E-Mail ZuoLiMD@Hotmail.com 
monly practiced in China than in other Dialysis Outcomes and Practice Patterns Study (DOPPS) countries. Finally, the use of ESAs manufactured in China (referred to here as 'domestic ESA') is widespread.

As part of our cross-sectional study of 45 hemodialysis units in 3 major metropolitan cities in China (Beijing, Guangzhou, and Shanghai), the DOPPS gathered data on patient- and facility-level anemia practices. We present patient-level data on the distribution of hemoglobin $(\mathrm{Hgb})$, markers of iron deficiency, and use of anemia-related medications in China DOPPS, with comparisons with North America and Japan. We also present data on a facility level on $\mathrm{Hgb}$ targets. We test whether some treatment practices seen more commonly in China than in other DOPPS countries, that is, less frequent monitoring, insufficient insurance for coverage of dialysis costs, and substantial use of 2-times weekly hemodialysis are associated with $\mathrm{Hgb}$ below $9 \mathrm{~g} / \mathrm{dl}$ in our study. Finally, we examine prescription patterns for anemia-related medications according to $\mathrm{Hgb}$ categories.

\section{Methods}

\section{Patients and Data Collection}

Begun in 1996, the DOPPS is an international prospective cohort study of hemodialysis patients $\geq 18$ years in Australia, Canada, Japan, New Zealand, the United States, and 7 European countries. Patients in the DOPPS are selected randomly from national samples of hemodialysis facilities in each country [10, 11]. In 2011, cross-sectional data were collected in China using the baseline DOPPS questionnaires and study protocols. Due to feasibility considerations, the China study was limited to representative data from the metropolitan areas in the 3 largest cities in China (Beijing, Guangzhou, and Shanghai). These cities were identified based on the feasibility of data collection and availability of registry information. Forty-five hemodialysis facilities (15 in each metropolitan area) were randomly selected from a comprehensive roster $(n=147)$ of hemodialysis units in the 3 metropolitan areas. Study approval and patient consent were obtained as required by national and local ethics committee regulations.

Clinical data were abstracted by a study coordinator at each participating site from patient records. Results of the most recent laboratories drawn prior to patient enrollment were abstracted. Medication prescription abstraction (active prescription at DOPPS enrollment) occurred at a median of 31 days (interquartile range, IQR 12-71 days) after the laboratory draw. Practice-level data were obtained through a survey administered to the medical director at each facility.

A total of 1,379 prevalent patients on hemodialysis in China sampled in 2011 were included in analyses and compared descriptively to 10,947 prevalent patients on hemodialysis sampled between 2009 and 2011 during DOPPS 4 in North America and Japan (excluded Europe DOPPS to simplify the presentation).

\section{Statistical Analysis}

Laboratory data for anemia markers were reported as both continuous values and categories created on the basis of the Kidney Disease Improving Global Outcomes (KDIGO) 2012 guidelines [12]. Standard descriptive statistics were used to describe other patient characteristics, treatment with intravenous iron and ESAs, and facility practices and directors' anemia biomarker targets. To account for patients dialyzing at a frequency other than 3 times per week, a standardized Kt/V was calculated from the equation reported by Leypoldt et al. [13]. When describing ESA dosing, darbepoetin alfa doses $(\mu \mathrm{g})$ were converted to intravenous epoetin alfa equivalent doses using a 200:1 conversion ratio. Subcutaneous erythropoietin (EPO) dosing was converted into an equivalent intravenous dosing by adding a $15 \%$ weighting.

The primary outcome in regression analysis among China DOPPS patients was $\mathrm{Hgb}<9 \mathrm{~g} / \mathrm{dl}$. The exposures of interest unique to China included: patient insurance status and frequency of dialysis sessions per week. Adjusted associations of these exposures with $\mathrm{Hgb}$ below $9 \mathrm{~g} / \mathrm{dl}$ were evaluated using generalized estimating equation (GEE) models accounting for facility clustering, and potential confounders including patient demographics, comorbidities, and laboratory characteristics, and facility-level anemia management (rather than patient-level) to reduce cross-sectional confounding by indication.

A second set of regression analyses were performed to measure the association of $\mathrm{Hgb}$ concentrations with prescription of anemia medications. GEE and linear mixed models, accounting for facility clustering, were used for medication use and dose outcomes respectively.

Variables included in models for the China patient population were generally missing for $<10 \%$ of patients, with the exception of C-reactive protein (CRP; 56\%), transferrin saturation (TSAT; $59 \%)$ and ferritin (34\%). For missing data, we used the sequential regression multiple imputation method implemented by IVEware [14], and analyzed using the MIAnalyze procedure in SAS/ STAT/9.3.

All analyses were conducted in SAS 9.3 (SAS Institute, Cary, N.C., USA).

\section{Results}

\section{Demographics and Cause of ESRD}

Compared with patients on hemodialysis in Japan and North America, patients in China DOPPS were younger, more likely to report the presence of residual kidney function, and less likely to have diabetic nephropathy listed as the cause of ESRD (table 1). The mean number of sessions per week and standardized Kt/V were lower in China DOPPS than in Japan and North America.

\section{Regional Comparison of Patient Anemia Markers}

Twenty-one percent of patients in China DOPPS had $\mathrm{Hgb}<9 \mathrm{~g} / \mathrm{dl}$, compared with $10 \%$ in Japan and $3 \%$ in North America (table 1). Twelve percent of patients in China's DOPPS had Hgb $<8 \mathrm{~g} / \mathrm{dl}$. Nearly all (93\%) pa- 
Table 1. Patient characteristics and anemia variables, by region

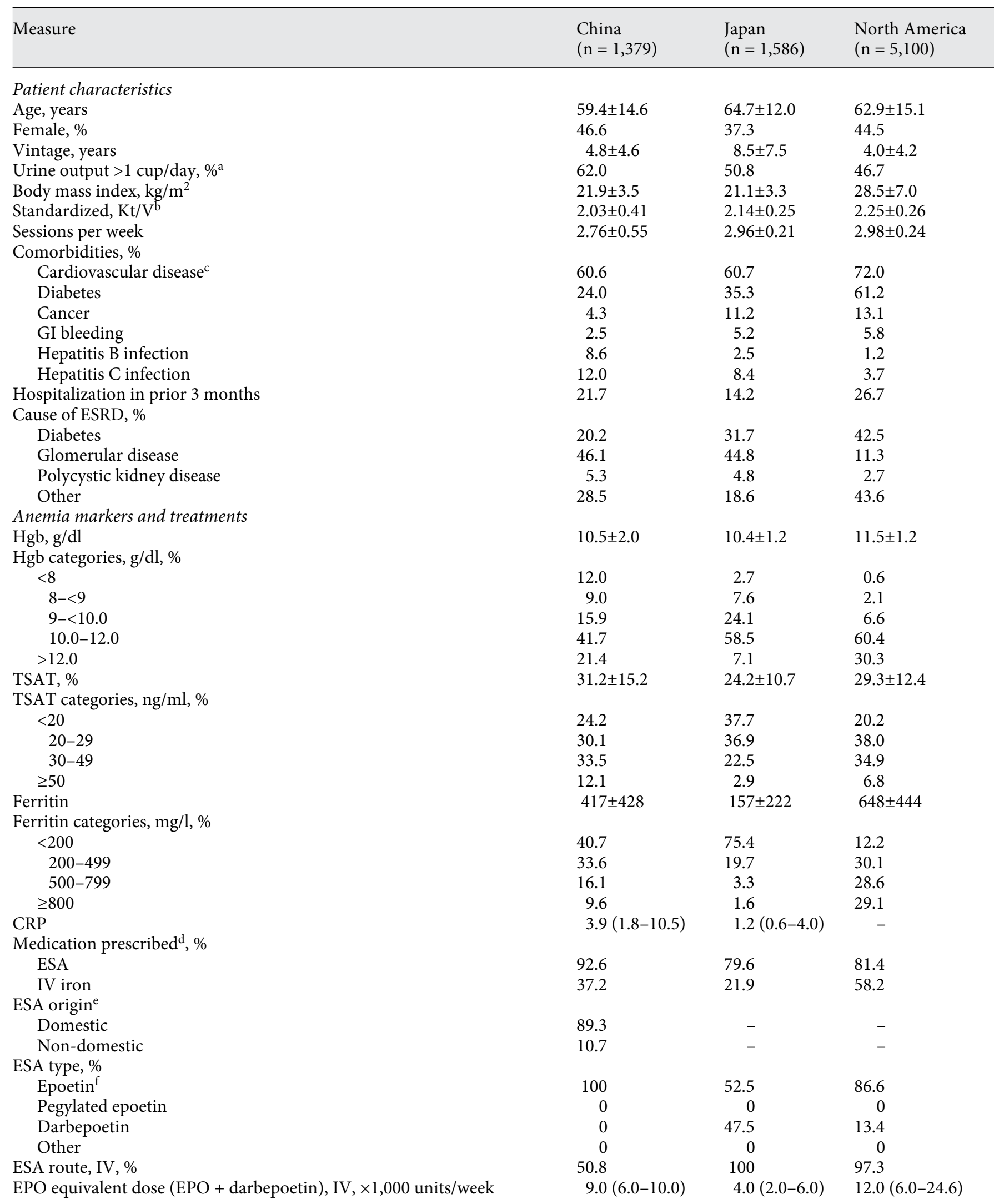


Table 2. Facility anemia management practices, by region

\begin{tabular}{lll}
$\begin{array}{l}\text { China } \\
(\mathrm{n}=45)\end{array}$ & $\begin{array}{l}\text { Japan } \\
(\mathrm{n}=58)\end{array}$ & $\begin{array}{l}\text { North America } \\
(\mathrm{n}=121)\end{array}$ \\
\hline
\end{tabular}

\section{Based on medical chart}

Median EPO alfa equivalent dose, $\times 1,000$ units/week $\%$ IV iron use

$9.6(7.5-11.5)$

$32.1(10.8-52.2)$
$4.0(3.0-4.3)$

$19.4(9.1-31.8)$

$12.0(8.0-16.5)$ $61.5(42.9-75.0)$

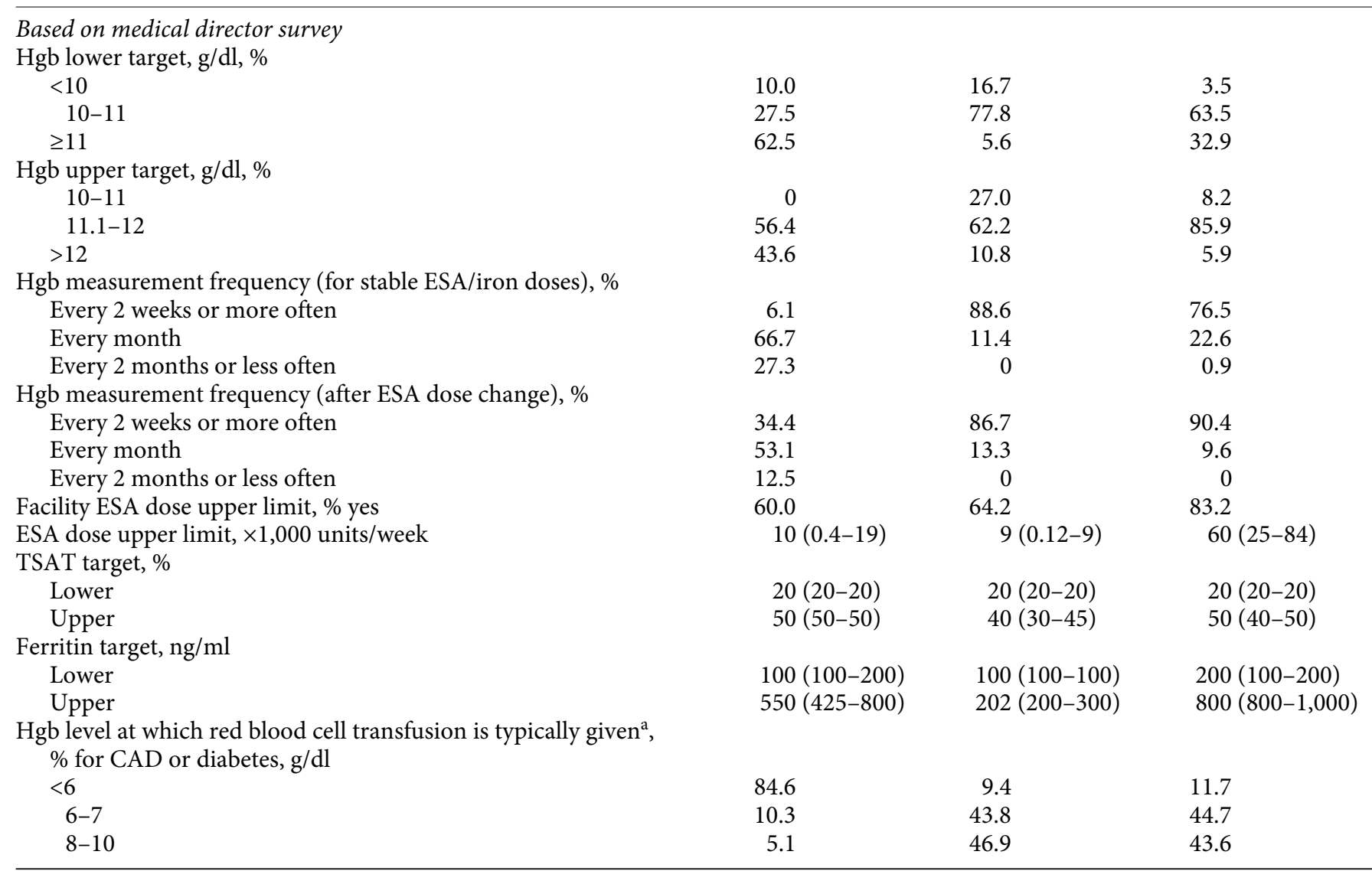

Continuous variables are shown as mean \pm SD or median (IQR). For patients without coronary artery disease or diabetes.

epoetin twice weekly or less often than in Japan $(53 \%)$ or North America (19\%).

Of note, there was a higher prevalence of hepatitis B and $\mathrm{C}$ in the China DOPPS patients, likely reflecting the higher general population seroprevalence of these viruses $[15,16]$.

Regional Comparison of Facility Anemia Management Consistent with patient-level data, $50 \%$ of facilities in China DOPPS had 23\% or more of patients with Hgb $<9 \mathrm{~g} / \mathrm{dl}$ (fig. 1), a higher proportion than in Japan (9\%) and North America (0\%). In Chinese facilities, there was large variability in this proportion: the lowest quartile of facilities had $7 \%$ or fewer patients with $\mathrm{Hgb}<9 \mathrm{~g} / \mathrm{dl}$, and the highest quartile of facilities had $30 \%$ or more patients with $\mathrm{Hgb}<9 \mathrm{~g} / \mathrm{dl}$.

A majority of medical directors in China DOPPS reported that their facilities targeted Hgb level at or above $11 \mathrm{~g} / \mathrm{dl}$, whereas medical directors in Japan and North America more commonly cited a target between 10 and $11 \mathrm{~g} / \mathrm{dl}$ (table 2). Most Chinese medical directors also reported a transfusion threshold of $\mathrm{Hgb}<6 \mathrm{~g} / \mathrm{dl}$, a more conservative threshold than in Japan and North America. Measurement of $\mathrm{Hgb}$ was most commonly performed monthly in most facilities in China, whereas in Japan and North America measurement was most commonly twice monthly or weekly. 
Fig. 2. a Median EPO dose, by Hgb category and region. $\mathbf{b}$ Percent of patients on IV iron, by Hgb category and region.

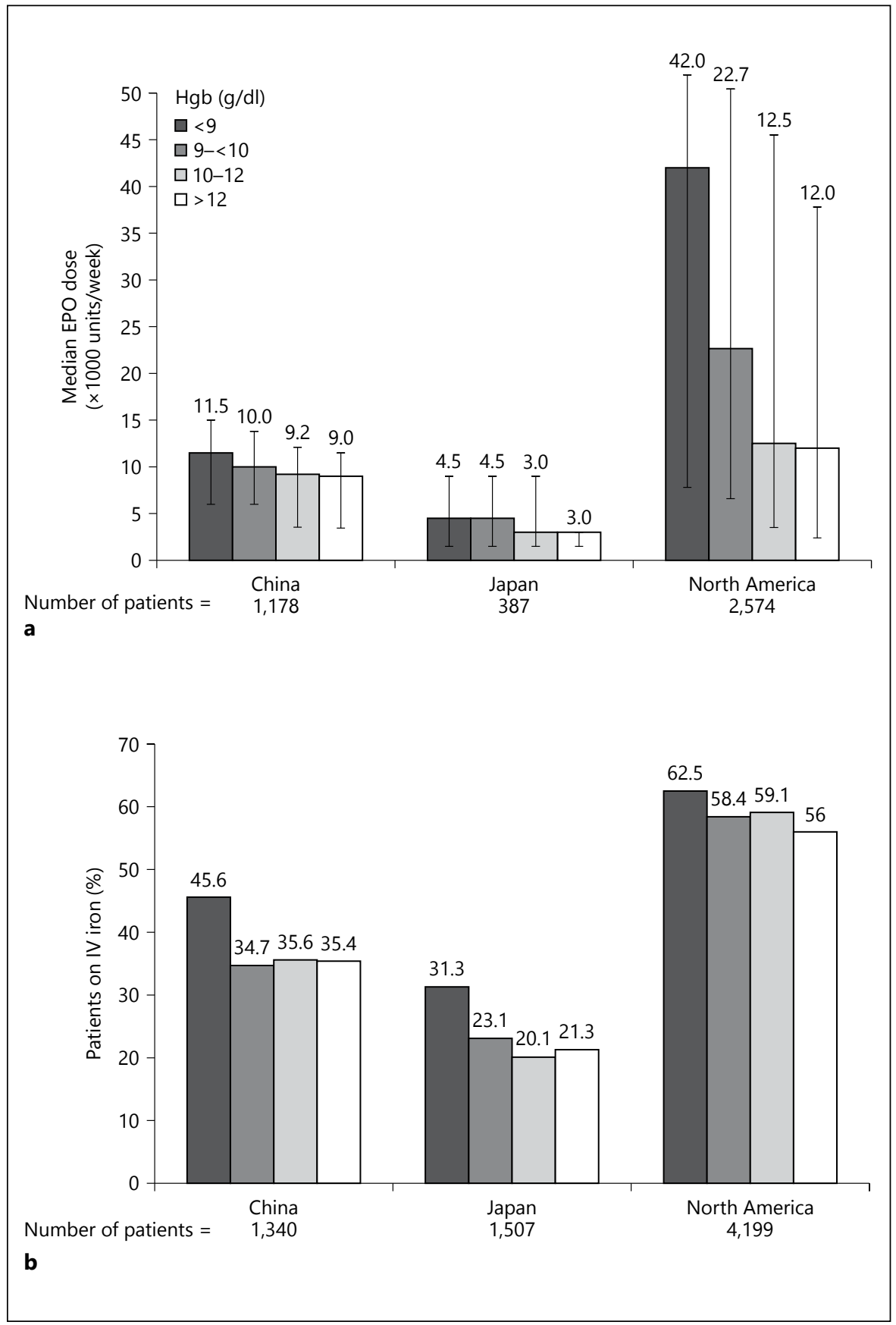

Patients in China DOPPS with $\mathrm{Hgb}<9 \mathrm{~g} / \mathrm{dl}$ received a dose of ESA 1.3-fold higher than patients with $\mathrm{Hgb}$ $10-12 \mathrm{~g} / \mathrm{dl}$; in North America and Japan the doses were 3.4- and 1.5-fold higher, respectively (fig. $2 \mathrm{a}$ ). The relative increase in prescription of intravenous iron for patients with ( $\mathrm{Hgb}<9$ vs. $10-12 \mathrm{~g} / \mathrm{dl})$ was $1.3-, 1.1-$, and 1.6-fold in China, North America, and Japan respectively (fig. 2b).
Patient and Facility Characteristics Associated with Anemia within the China DOPPS

Patients in China DOPPS had higher odds of Hgb below $9 \mathrm{~g} / \mathrm{dl}$ if they were female, had lower BMI, or had been hospitalized in the prior 3 months (table 3). Use of a catheter (as opposed to fistula or graft), undergoing fewer than 3 sessions per week, not having a majority of care covered by insurance, lower serum albumin, TSAT $<20 \%$, 
Table 3. Patient characteristics by Hgb category, in the China DOPPS

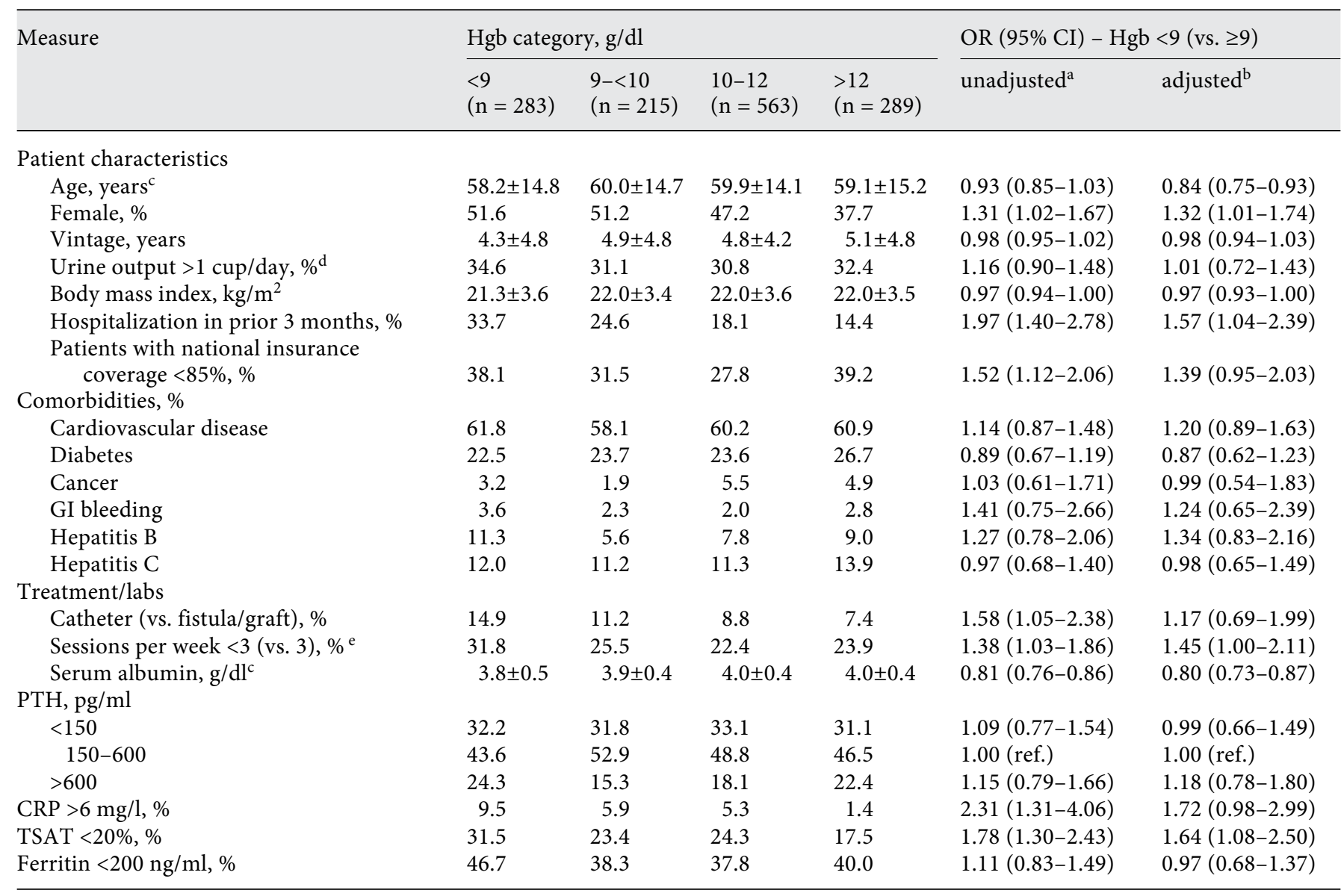

\footnotetext{
${ }^{a}$ Unadjusted GEE model accounting for facility clustering.

${ }^{\mathrm{b}}$ Adjusted GEE model accounting for facility clustering and adjusted for all variables listed in the table as well as facility anemia management variables (median EPO dose, facility percentage of patients prescribed IV iron, facility percentage of patients with ferritin or TSAT measured in the last month, frequency of checking Hgb).

${ }^{c}$ ORs are per 10 years older for age per $0.2 \mathrm{~g} / \mathrm{dl}$ for serum albumin.

d Among all patients.

${ }^{\mathrm{e}}$ In a sensitivity analysis restricted to patients dialyzing 3 times per week, the unadjusted and adjusted OR ( $\left.95 \% \mathrm{CI}\right)$ of $\mathrm{Hgb}<9 \mathrm{~g} / \mathrm{dl}$ (vs. $\geq 9)$ per 0.2 unit increase in single pool Kt/V was 0.91 (0.81-1.03), $0.88(0.74-1.04)$, respectively. The adjusted OR (95\% CI) of $\mathrm{Hgb}<9 \mathrm{~g} / \mathrm{dl}$ (vs. $\geq 9$ ) for sessions per week $<3$ (vs. 3) was 1.57 (1.12-2.21) without adjusting for gender, residual kidney function, and patient insurance (co-linear characteristics). The adjusted OR (95\% CI) of $\mathrm{Hgb}<9 \mathrm{~g} / \mathrm{dl}$ (vs. $\geq 9$ ) for insurance $<85 \%$ (vs. $\geq 85 \%$ ) was 1.49 (1.02-2.18) without adjusting for gender, residual kidney function, and sessions per week (co-linear characteristic).
}

or CRP $>6 \mathrm{mg} / \mathrm{l}$ were also associated with higher odds of Hgb below $9 \mathrm{~g} / \mathrm{dl}$.

In a model adjusting for patient, treatment, and facility characteristics, the associations of catheter use, CRP, and insurance coverage with $\mathrm{Hgb}<9 \mathrm{~g} / \mathrm{dl}$ were modestly attenuated. Younger patients had higher odds of $\mathrm{Hgb}$ $<9 \mathrm{~g} / \mathrm{dl}$ in this adjusted model.

When examining facility characteristics, we found that patients in facilities that routinely checked $\mathrm{Hgb}$ every 2 weeks or more often (as compared with monthly) had higher mean $\mathrm{Hgb}$ (fig. 3). Mean patient Hgb did not differ according to facility mean ESA dose (online suppl. figure 1; for all online suppl. material, see www.karger. com/doi/10.1159/000442741) or percentage of patients prescribed IV iron (online suppl. fig. 2).

\section{Prescription of Anemia-Related Medications \\ According to Hgb Categories within China DOPPS}

There was an increase in odds of intravenous iron use among patients in China DOPPS with $\mathrm{Hgb}<9 \mathrm{~g} / \mathrm{dl}$ com- 
Table 4. Anemia management decisions, by Hgb categories in the China DOPPS

\begin{tabular}{|c|c|c|c|c|}
\hline Hemoglobin, $\mathrm{g} / \mathrm{dl}^{\mathrm{a}}$ & $\begin{array}{l}\text { ESA use, } \\
\text { OR }(95 \% \text { CI })\end{array}$ & $\begin{array}{l}\text { ESA dose }{ }^{a}, \\
\beta(95 \% \mathrm{CI})\end{array}$ & $\begin{array}{l}\text { Branded ESA use (vs. } \\
\text { domestic) }^{\mathrm{c}}, \text { OR }(95 \% \mathrm{CI})\end{array}$ & $\begin{array}{l}\text { IV Iron use }{ }^{\mathrm{b}} \\
\text { OR }(95 \% \mathrm{CI})\end{array}$ \\
\hline$<9$ & $1.03(0.50-2.12)$ & $1,204$ (249 to 2,159$)$ & $1.04(0.75-1.44)$ & $1.22(0.94-1.59)$ \\
\hline $9-<10$ & $0.84(0.43-1.65)$ & $598(-559$ to 1,755$)$ & $0.83(0.53-1.30)$ & $1.02(0.77-1.36)$ \\
\hline $10-12$ & 1 (ref.) & 0 (ref.) & 1 (ref.) & 1 (ref.) \\
\hline$>12$ & $0.37(0.18-0.75)$ & $-405(-1,206$ to 396$)$ & $0.79(0.48-1.29)$ & $0.92(0.71-1.20)$ \\
\hline Continuous, per g/dl & $0.79(0.66-0.95)$ & $-256(-431$ to -81$)$ & $0.95(0.84-1.07)$ & $0.94(0.90-0.99)$ \\
\hline
\end{tabular}

Each column is a separate model adjusted for variables in table 3 with the exception of facility anemia management variables; accounting for facility clustering.

${ }^{a}$ ESA dose is expressed in units/week.

${ }^{\mathrm{b}} \mathrm{OR}(95 \% \mathrm{CI})$ for $\mathrm{Hgb}<9 \mathrm{~g} / \mathrm{dl}$ (vs. $\left.\geq 9\right)$ is $1.23(0.97-1.57)$.

${ }^{\mathrm{c}}$ Restricted to patients on ESA use.

Fig. 3. Distribution of patient Hgb, by frequency of measuring Hgb in China DOPPS facilities.

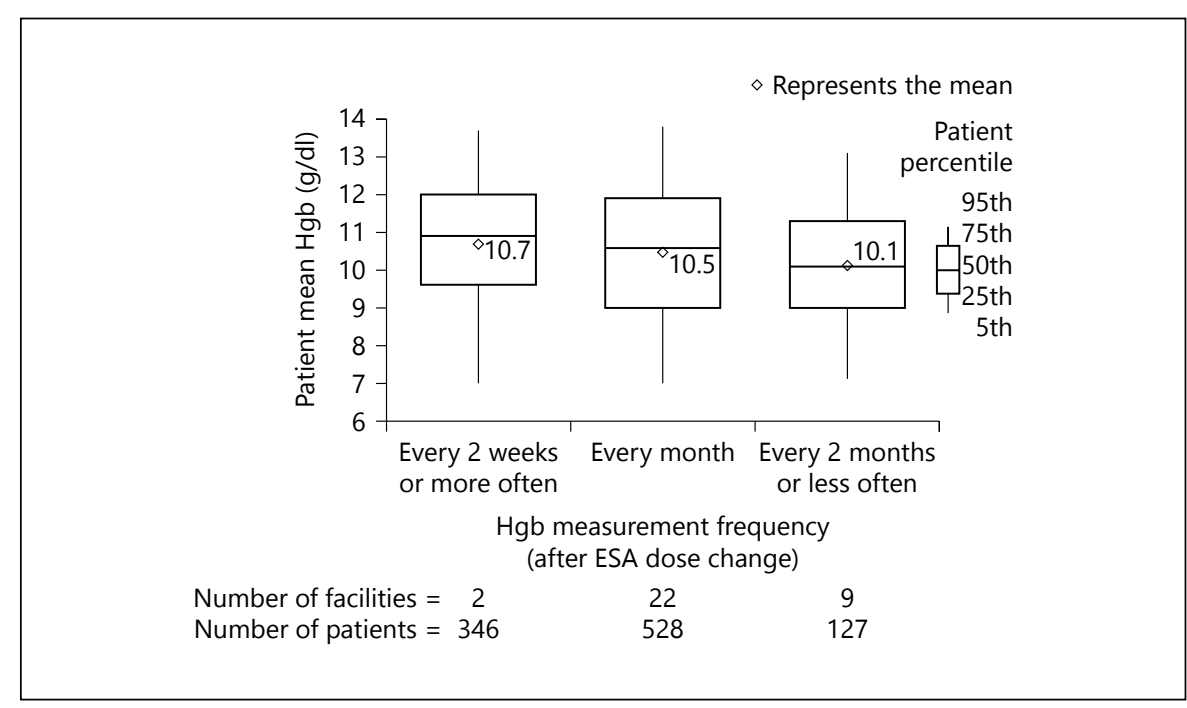

pared with patients with $\mathrm{Hgb} 10-12 \mathrm{~g} / \mathrm{dl}$ (table 4). Patients with $\mathrm{Hgb}>12 \mathrm{~g} / \mathrm{dl}$ were less likely to receive an ESA, compared to Hgb 10-12 g/dl. Patients with $\mathrm{Hgb}<9 \mathrm{~g} / \mathrm{dl}$ received a higher dose of ESA (1,204 units per week increase in dose), compared with patients with Hgb 10$12 \mathrm{~g} / \mathrm{dl}$.

\section{Discussion}

In our cross-sectional study of representative data from 3 major metropolitan areas in China, we found that a substantial proportion of patients on hemodialysis have low $\mathrm{Hgb}$ concentrations. In addition to some well-known patient correlates of anemia - such as systemic inflamma- tion or recent illness - we found that treatment practices more common in China than in other DOPPS countries, such as the use of less than 3 times weekly hemodialysis and patient financial contribution toward therapy, also likely contributed to the higher odds of $\mathrm{Hgb}<9 \mathrm{~g} / \mathrm{dl}$. Strikingly, the prevalence of $\mathrm{Hgb}<9 \mathrm{~g} / \mathrm{dl}$ was high despite DOPPS Chinese facility directors reporting a higher target for serum Hgb than many of their Japanese or North American counterparts. In this context, the relative increase in ESA dose in patients with $\mathrm{Hgb}<9 \mathrm{~g} / \mathrm{dl}$ was considerably lower in China DOPPS than in North America.

Some patient characteristics that were associated with higher odds of $\mathrm{Hgb}$ below $9 \mathrm{~g} / \mathrm{dl}$ in our model were as expected: hospitalization in the prior 3 months, higher CRP, and lower serum albumin and TSAT. Interestingly, we
Zuo et al. 
found that older patients on dialysis had lower odds of Hgb below $9 \mathrm{~g} / \mathrm{dl}$. Though counter-intuitive, an association between older age and lower odds of low Hgb concentrations has been consistently reported in analyses of patients undergoing hemodialysis in Europe, North America, and Japan $[17,18]$ and may reflect a lower physician tolerance for 'significant' anemia among older patients.

We had hypothesized that $\mathrm{Hgb}$ targets may be difficult to meet in China due to financial constraints for the government system and patients who do not have full national insurance coverage, thereby limiting the laboratory monitoring and frequency of dialysis. Our data largely support these hypotheses. We found modest associations among lower insurance coverage and lower frequency of hemodialysis, and higher likelihood of $\mathrm{Hgb}<9 \mathrm{~g} / \mathrm{dl}$. Patients receiving fewer than 3 sessions a week of hemodialysis in China are less likely to meet dialysis 'adequacy' targets (typically Kt/V urea) [9], raising the possibility of ESA hyporesponsiveness $[9,19]$. Frequency of ESA administration is also likely lower among patients not receiving hemodialysis at least 3 times weekly. Few Chinese DOPPS facilities undertook 2 times per month Hgb monitoring, with patients in these facilities having slightly higher mean $\mathrm{Hgb}$ concentrations. While we cannot make firm conclusions based on our data alone, data from other DOPPS countries have shown that more frequent $\mathrm{Hgb}$ monitoring and review of ESA dose are associated with lower facility-level variation in $\mathrm{Hgb}$ [20].

Findings from the medical director survey in North America and Japan were consistent with nephrologists in these countries following the most current anemia guidelines of KDIGO (2012) [12] and/or the Japanese Society of Dialysis and Transplantation (JSDT, 2008) [17]. Both societies recommend more conservative management than advised in the 2007 National Kidney Foundation/ Kidney Disease Outcomes Quality Initiative (NKF/ KDOQI) [18], with KDIGO generally advising the use of ESAs once Hgb falls below $10 \mathrm{~g} / \mathrm{dl}$. Concordantly, a majority of medical directors in North America and Japan expressed a targeted Hgb between 10 and $11 \mathrm{~g} / \mathrm{dl}$. However, in Japan a substantially higher proportion of patients had Hgb below $10 \mathrm{~g} / \mathrm{dl}$ and lower doses of ESAs were used than in North America. As we have previously discussed, lower Hgb concentrations and low-dose ESA use in Japan appears to stem from a historically lower $\mathrm{Hgb}$ target set by the JSDT. An emphasis on a cautious approach to anemia management in the country continues and includes reimbursement caps for weekly ESA doses [21].

Anemia in China DOPPS
In contrast, it appears that the target of Hgb concentrations above $11 \mathrm{~g} / \mathrm{dl}$, which a majority of Chinese nephrologists in the DOPPS study endorse, is most consistent with the $2007 \mathrm{NKF} / \mathrm{KDOQI}$ guidelines. A survey of Chinese nephrologists confirmed reliance on NKF/ KDOQI guidelines for most hemodialysis-related practices [22]. A consensus statement from experts in China, published after the period of our data collection, also recommends targets of 11-13 g/dl [7]. A majority of patients on hemodialysis in China's DOPPS do not meet this target, with more than a third having Hgb concentrations below $10 \mathrm{~g} / \mathrm{dl}$ and more than half with Hgb below $11 \mathrm{~g} /$ dl. At the same time, Chinese nephrologists demonstrated a high tolerance for anemia, recommending a transfusion only when $\mathrm{Hgb}$ falls below $6 \mathrm{~g} / \mathrm{dl}$. This reluctance to transfuse may indicate a concern about the safety of blood products [23]. It also demonstrates that while the China DOPPS nephrologists expressed higher Hgb targets, they seem to clinically accept a wide range of $\mathrm{Hgb}$ concentrations.

We found that ESA use was nearly ubiquitous in China's DOPPS, similar to Japan and North America. However, we noted 3 major differences in the use of ESAs in China when compared with North America in particular. First, the type of ESA used in China is exclusively epoetin, predominantly domestically manufactured. These are ESAs produced in China that have gone through regulatory approval from the China Food and Drug Administration Board. A biochemical analysis performed in 2009 of domestically manufactured ESAs from Korea, China, and India reported that these products have more impurities and less reliable potency when matched to labeled concentration [24]. An updated and confirmatory analysis of this nature is crucial, as more than 50 ESA products are available in China, and their costs are reported to be about one third (or less) of branded epoetin alfa $[25,26]$. In the current study, we unfortunately could not assess the effect of domestic vs. branded ESA prescription on $\mathrm{Hgb}$ concentrations due to the lack of facility-level variation in ESA type. The longitudinal China's DOPPS, begun in late 2012, will provide more appropriate data to explore this relationship.

Second, the route of erythropoietin delivery was subcutaneous in nearly half of the patients on hemodialysis in China's DOPPS, a much larger proportion than in Japan and North America. The subcutaneous route of administration has been purported to be more efficient (i.e. lower total dose required to exert a given effect) [27], potentially helping to defray cost of ESA therapy [28]. However, concerns about safety and financial incentives to use 
injectable drug therapy have precluded widespread use in the United States $[29,30]$.

Third, median doses of ESA increased only modestly for patients with $\mathrm{Hgb}<9 \mathrm{~g} / \mathrm{dl}$ compared with patients with $\mathrm{Hgb} 10-12 \mathrm{mg} / \mathrm{dl}$, in contrast to the variation observed in North America. This lack of variation in dosing in China DOPPS could be related to cost considerations, doubts about effectiveness, and/or concerns about side effects such as worsening of hypertension control on high doses of ESA.

Our study has several strengths. It presents detailed and systematically collected data on practices related to anemia management for patients on hemodialysis in 3 major metropolitan areas within China. With the medical director survey, we were also able to put these practices in the context of expressed targets and facility practices. Since there was a median lag of about a month between laboratory values and medication abstraction, we could assess for physician response to the laboratory values. We were also able to compare anemia management in 3 of China's major metropolitan areas with practices in other countries.

One key limitation of the study is that we do not capture data on patients undergoing hemodialysis in smaller cities or non-urban areas. CRP, TSAT, and ferritin were not routinely measured in many facilities in the China DOPPS and were therefore missing for 56,59 , and $34 \%$ of patients, respectively. However, to avoid the potential biases of complete case analyses, we used sequential regression multiple imputation to impute missing values. During this phase of the study, we did not specifically ascertain data on oral iron use. Preliminary data from the longitudinal phase indicate higher oral iron use in China than other DOPPS regions. Also, we did not ascertain patient-level transfusion data in this phase of the study. From the longitudinal phase, we know that a majority of transfusions in China occur outside of the dialysis unit and therefore may not be reliably captured. Finally, while table 1 presents mean equivalent EPO dose across the 3
DOPPS countries, dosing data from China may not be directly comparable given the higher reliance on biosimilar ESAs.

In summary, our study highlights a large gap between expressed target and achieved Hgb in patients on hemodialysis in the China DOPPS. Less frequent hemodialysis, patient financial contribution to therapy, and a lack of substantial increase in ESA dose at lower Hgb concentrations may partially explain this gap. With the publication of the recent consensus Chinese guidelines [7], we may begin to see improved monitoring and calibration of ESA to meet targets. Further studies in this country with an emerging dialysis practice serving a large number of patients are crucial to determine improvements in achievement of anemia targets, as well as associations with patient outcomes.

\section{Acknowledgements}

We are grateful to Dr. Haiyan Wang of Peking University First Hospital (Beijing, China) who provided insight before her untimely death. Dr. S. Anand is supported by NIDDK 5K23DK101826.

\section{Sources of Support}

The DOPPS program is supported by Amgen, Kyowa Hakko Kirin, AbbVie Inc., Sanofi Renal, Baxter Healthcare, and Vifor Fresenius Medical Care Renal Pharma, Ltd. Additional support for specific projects and countries is also provided in Canada by Amgen, BHC Medical, Janssen, Takeda, Kidney Foundation of Canada (for logistics support); in Germany by Hexal, DGfN, Shire, WiNe Institute; for PDOPPS in Japan by the Japanese Society for Peritoneal Dialysis (JSPD). All support is provided without restrictions on publications. S.A. is funded by NIDDK K23 DK101826-01.

\section{Disclosure Statement}

The authors have no conflicts of interest to declare.

\section{References}

1 Ibrahim HN, Ishani A, Foley RN, Guo H, Liu J, Collins AJ: Temporal trends in red blood transfusion among US dialysis patients, 1992-2005. Am J Kidney Dis 2008;52:11151121.

2 Levin NW, Lazarus JM, Nissenson AR: National Cooperative rHu Erythropoietin Study in patients with chronic renal failure - an interim report. The National Cooperative $\mathrm{rHu}$
Erythropoietin Study Group. Am J Kidney Dis 1993;22(2 suppl 1):3-12.

3 Beusterien KM, Nissenson AR, Port FK, Kelly M, Steinwald B, Ware JE Jr: The effects of recombinant human erythropoietin on functional health and well-being in chronic dialysis patients. J Am Soc Nephrol 1996;7:763-773.

4 United States Renal Database. USRDS Atlas: Costs of ESRD, 2012
5 Baboolal K, McEwan P, Sondhi S, Spiewanowski P, Wechowski J, Wilson K: The cost of renal dialysis in a UK setting - a multicentre study. Nephrol Dial Transplant 2008; 23:1982-1989.

6 Zuo L, Wang M: Current burden and probable increasing incidence of ESRD in China. Clin Nephrol 2010;74(suppl 1):S20S22. 
7 Chinese expert consensus group on renal anemia diagnosis and management: Diagnosis and management of renal anemia: China expert consensus 2013. Chin J Nephrol 2013;29: 389-392.

8 Lin S: Nephrology in China: a great mission and momentous challenge. Kidney Int Suppl 2003;83:S108-S110.

9 Bieber B, Qian J, Anand S, Yan Y, Chen N, Wang M, Wang M, Zuo L, Hou FF, Pisoni RL, Robinson BM, Ramirez SP: Two-times weekly hemodialysis in China: frequency, associated patient and treatment characteristics and quality of life in the China Dialysis Outcomes and Practice Patterns Study. Nephrol Dial Transplant 2014;29:1770-1777.

10 Young EW, Goodkin DA, Mapes DL, Port FK, Keen ML, Chen K, Maroni BL, Wolfe RA, Held PJ: The Dialysis Outcomes and Practice Patterns Study (DOPPS): an international hemodialysis study. Kidney Int 2000;57:S74S81.

11 Pisoni RL, Gillespie BW, Dickinson DM, Chen K, Kutner MH, Wolfe RA: The dialysis outcomes and practice patterns study (DOPPS): design, data elements, and methodology. Am J Kidney Dis 2004;44(5 suppl 2):7-15.

12 http://www.kdigo.org/clinical_practice_ guidelines/pdf/KDIGO-Anemia\%20GL.pdf.

13 Leypoldt JK, Jaber BL, Zimmerman DL: Predicting treatment dose for novel therapies using urea standard Kt/V. Semin Dial 2004;17: 142-145.

14 Raghunathan TE, Solenberger PW, Hoewyk JV: IVEware: Imputation and Variance Estimation Software User Guide, 2002.

15 Ji Z, Wang T, Shao Z, Huang D, Wang A, Guo Z, Long Y, Zhang L, Su H, Zhang Q, Yan Y, Fan D: A population-based study examining hepatitis B virus infection and immunization rates in Northwest China. PLoS One 2014; 9:e97474.
16 Xuezhong L, Naitoh S, Xuewen D, Song W, San Q, Li L, Hong T, Liansan Z, Bingjun L, Akahane Y: Prevalence of hepatitis $C$ virus infection in the general population and patients with liver disease in China. Hepatol Res 1999; 14:135-143.

17 Tsubakihara Y, Nishi S, Akiba T, Hirakata H, Iseki K, Kubota M, Kuriyama S, Komatsu Y, Suzuki M, Nakai S, Hattori M, Babazono T, Hiramatsu $M$, Yamamoto $H$, Bessho $M$, Akizawa T: 2008 Japanese society for dialysis therapy: guidelines for renal anemia in chronic kidney disease. Ther Apher Dial 2010;14: 240-275.

18 www.kidney.org/professionals/kdoqi/ guidelines_anemia/cpr21.htm.

19 Madore F, Lowrie EG, Brugnara C, Lew NL, Lazarus JM, Bridges K, Owen WF: Anemia in hemodialysis patients: variables affecting this outcome predictor. J Am Soc Nephrol 1997;8: 1921-1929.

20 Pisoni RL, Bragg-Gresham JL, Fuller DS, Morgenstern H, Canaud B, Locatelli F, Li Y, Gillespie B, Wolfe RA, Port FK, Robinson BM: Facility-level interpatient hemoglobin variability in hemodialysis centers participating in the Dialysis Outcomes and Practice Patterns Study (DOPPS): associations with mortality, patient characteristics, and facility practices. Am J Kidney Dis 2011;57:266-275.

21 Akizawa T, Pisoni RL, Akiba T, Saito A, Fukuhara S, Asano Y, Hasegawa T, Port FK, Kurokawa $\mathrm{K}$ : Japanese haemodialysis anaemia management practices and outcomes (19992006): results from the DOPPS. Nephrol Dial Transplant 2008;23:3643-3653.

22 Wang $\mathrm{H}$, Zhang L, Lv J: Prevention of the progression of chronic kidney disease: practice in China. Kidney Int Suppl 2005;94:S63-S67.
23 Song Y, Bian Y, Petzold M, Ung CO: Prevalence and trend of major transfusion-transmissible infections among blood donors in western China, 2005 through 2010. PLoS One 2014;9:e94528.

24 Park SS, Park J, Ko J, Chen L, Meriage D, Crouse-Zeineddini J, Wong W, Kerwin BA: Biochemical assessment of erythropoietin products from Asia versus US Epoetin alfa manufactured by Amgen. J Pharm Sci 2009; 98:1688-1699.

25 Wu J, Yuan Z, Ye C, Li Y, Sun L, Mei C: High dose of rhEPO in treatment of uremic anemia. Acad J Sec Mil Med Univ 2002;23:1243-1245.

26 Decreasing Market Price of Recombinant Human Erythropoietin EPO in China, 2001. h t t p: / / www.biosino.org/news 2001/20013/01030618.htm.

27 Kaufman JS, Reda DJ, Fye CL, Goldfarb DS, Henderson WG, Kleinman JG, Vaamonde CA: Subcutaneous compared with intravenous epoetin in patients receiving hemodialysis. Department of veterans affairs cooperative study group on erythropoietin in hemodialysis patients. N Engl J Med 1998;339: 578-583.

28 Besarab A, Reyes CM, Hornberger J: Metaanalysis of subcutaneous versus intravenous epoetin in maintenance treatment of anemia in hemodialysis patients. Am J Kidney Dis 2002;40:439-446.

29 Pollock C, Johnson DW, Hörl WH, Rossert J, Casadevall N, Schellekens H, Delage R, De Francisco A, Macdougall I, Thorpe R, Toffelmire E: Pure red cell aplasia induced by erythropoiesis-stimulating agents. Clin J Am Soc Nephrol 2008;3:193-199.

30 Thamer M, Zhang Y, Kaufman J, Stefanik K, Cotter DJ: Factors influencing route of administration for epoetin treatment among hemodialysis patients in the United States. Am J Kidney Dis 2006;48:77-87. 